3 Antó JM, Sunyer J, Rodríguez-Roisín R, Suarez-Cervera M Vázquez L. Community outbreaks of asthma associated with inhalation of soybean dust. $N$ Engl f Med 1989;320: with inhalation.

4 Antó JM, Sunyer J, Reed CE, Sabrià J, Martínez F, Morell $\mathrm{F}$, et al. Preventing asthma epidemics due to soybeans by dust-control measures. $N$ Engl f Med 1993;329:1760-3.

5 Martinez F, Sunyer J, Antó JM. Reliability of a monitoring system for respiratory emergency room admissions. Eur Respir f 1993;6:337-41.

6 Swanson MC, Li JT, Wentz-Murtha PE, Trudeau WL, Fernandez-Caldas E, Griefe A, et al. Source of the aeroallergen of soybean dust: a low molecular mass glycopeptide from the soybean tela. $f$ Allergy Clin Immunol 1991;87:783-8.

7 Aceves M, Grimalt JO, Sunyer J, Antó JM, Reed CE. Identification of soybean dust as an epidemic asthma agent in urban areas by molecular marker and RAST analysis of urban areas by molecular marker and 7 Allergy Clin Immunol 1991;88:124-34.

8 Antó JM, Sunyer J. Epidemiologic studies of asthma epidemics in Barcelona. Chest 1990;98:185-95S.

9 Sabrià J, Antó JM, Sunyer J, Roca J, Morell F, RodríguezRoisin $\mathrm{R}$, et al. Clinical and functional characteristics of patients two years after being affected by the soybean asthma epidemic in Barcelona. Thorax 1994;49:906-9.

Thorax 1995;50:1103-1105

\title{
Review of the prescription of domiciliary long term oxygen therapy in Scotland
}

\author{
D Morrison, K Skwarski, W MacNee
}

\begin{abstract}
Background - Since 1989 long term oxygen therapy (LTOT) in Scotland has been prescribable only by respiratory physicians, whereas in England and Wales general practitioners can also prescribe this treatment. The effect of this policy has been audited.

Method - Six hundred and thirty patients were prescribed LTOT in Scotland between 1 October 1989 and 30 September 1991, of which 519 case notes were reviewed.

Results - In $79 \%$ of patients the diagnosis was chronic obstructive pulmonary disease (COPD), with a near equal male to female ratio. The mean (SD) age was 65 (13) years (range $0 \cdot 2-90$ ). Sixty percent of patients died during the study period. Compliance with treatment was $14.9(6 \cdot 0)$ hours daily (range 1-24) and in $44 \%$ was less than 15 hours daily. Sixty one percent were clinically unstable when assessed and $14 \%$ were still smoking. Only $14 \%$ of those with COPD fulfilled all of the relative criteria for the prescription of LTOT. Only $56 \%$ had a repeated arterial blood gas measurement within 12 months of prescription and $51 \%$ of these were taken during a period of clinical instability. Expenditure on oxygen cylinders was six times greater than on oxygen concentrators over this period.

Conclusions - Compliance with LTOT in Scotland, where prescription is the responsibility of respiratory physicians, is similar to other studies and ranges widely. The greatest problem concerning adherence to the guidelines is assessment during clinical instability. The number of deaths suggest that prescription occurs late in the course of the disease. This study highlights the areas where the prescription of LTOT needs to be improved.

(Thorax 1995;50:1103-1105)
\end{abstract}

Keywords: domiciliary oxygen, audit, chronic obstructive pulmonary disease.
Long term oxygen therapy (LTOT) prolongs survival in patients with chronic obstructive pulmonary disease (COPD) and respiratory failure. ${ }^{1}$ In 1985 the Department of Health issued guidelines in England and Wales for the prescription of LTOT by oxygen concentrator by general practitioners. ${ }^{2}$ In October 1989 these guidelines were modified by the Scottish Home and Health Department (SHHD). The main change was that only respiratory physicians would be allowed to prescribe LTOT in Scotland. ${ }^{3}$ This has provided an opportunity to audit whether this change in policy has had a beneficial effect.

\section{Methods}

A data base was established on all 630 patients who were prescribed LTOT by oxygen concentrator monitored centrally by the Common Services Agency (CSA) between 1 October 1989 and 30 September 1991 . We reviewed the case notes of 519 of these patients and assessed prescription criteria and follow up arrangements. Patients were regarded as clinically unstable during an exacerbation of their respiratory condition and for six weeks thereafter. Evidence for an exacerbation was taken from the physician's written opionion in the case notes or, when not available, the presence of purulent sputum or the prescription of an antibiotic. Compliance data were provided by the CSA in the form of three monthly oxygen concentrator meter returns. The number of deaths was recorded over three years from the start of the study.

\section{Results}

Between 1 October 1989 and 30 September 1991632 concentrators were prescribed to 630 patients in Scotland with almost equal numbers of men and women ( $\mathrm{M}: \mathrm{F} 310: 320)$. The prescription rate in relation to the population was greatest in the main urban areas. Twenty one patients were prescribed LTOT because of excessively high cylinder use. Twenty one concentrators were withdrawn, seven because of 
Table 1 Absolute and relative SHHD criteria for the prescription of LTOT in Scotland

\begin{tabular}{ll}
\hline Absolute: & $\mathrm{FEV}_{1}<1.51$ \\
& $\mathrm{PaO}_{2}<7 \cdot 3 \mathrm{kPa}$ \\
& $\mathrm{PaCO}_{2}>6 \cdot 0 \mathrm{kPa}$ \\
& Oedema \\
& Clinically stable \\
& Repeated measurements \\
& Optimal therapy \\
& No smoking \\
Relative: & As above without hypercapnia or oedema
\end{tabular}

$\mathrm{FEV}_{1}=$ forced expiratory volume in one second; $\mathrm{PaO}_{2}, \mathrm{PaCO}_{2}=$ arterial oxygen and carbon dioxide tensions.

poor compliance and 14 because the patient no longer met the criteria for LTOT.

Complete information was obtained from 519 case notes. In a few of the remaining 111 cases the information in the case notes was inadequate for our purposes, but the majority were not sent to us. There was no particular health board bias in this. Thus, a representative group of patients was assessed.

The SHHD guidelines are shown in table 1. In $79 \%$ of patients the diagnosis was COPD and, of the remaining $21 \%, 13 \%$ had pulmonary fibrosis and only $1 \%$ were paediatric cases. Our findings relate to all diagnoses (table 2). Mean (SD) concentrator use was $14.9(6.0)$ hours daily and ranged from one to 24 hours (figure). The concentrator was used by $44 \%$ of patients for $<15$ hours each day. Sixty one percent of patients were assessed when clinically unstable, as defined above, and 33\% were assessed as an inpatient at the end of an exacerbation. Oedema was present at the time of assessment in $36 \%$ of cases who were also therefore clinically unstable by definition. In only $6 \%$ of cases were measurements of spirometric parameters and arterial blood gases repeated with an interval of at least three weeks as stated in the guidelines. Fourteen percent of patients were current smokers at prescription.

In those patients with COPD only $14 \%$ fitted all of the relative criteria for the prescription of LTOT if repeated measurements of arterial blood gas values and spirometric parameters three or more weeks apart are disregarded. In $2 \%$ the forced expiratory volume in one second $\left(\mathrm{FEV}_{1}\right)$ was $\geqslant 1.51$ and in $22 \%$ it was not

Table 2 Mean (SD) and range of patient characteristics at the time of assessment for LTOT

\begin{tabular}{ll}
\hline $\mathrm{n}$ & 519 \\
$\mathrm{M}: \mathrm{F}$ & $256: 263$ \\
Mean (SD) age (years) & $65(13)$ \\
Range & $0 \cdot 2-90$ \\
$>70$ years & $161(31 \%)$ \\
& $0 \cdot 8(0 \cdot 5)$ \\
$\mathrm{FEV}_{1}(\mathrm{l})$ & $0 \cdot 1-3 \cdot 6$ \\
$\mathrm{FVC}(\mathrm{l})$ & $1 \cdot 7(0 \cdot 7)$ \\
& $0 \cdot 2-4 \cdot 8$ \\
$\mathrm{Breathing} \mathrm{air}_{\mathrm{PaO}_{2}(\mathrm{kPa})}$ & \\
$\mathrm{PaCO}_{2}(\mathrm{kPa})$ & $6 \cdot 5(1 \cdot 3)$ \\
& $2 \cdot 9-12 \cdot 9$ \\
$\mathrm{Breathing} \mathrm{oxygen}$ & $6 \cdot 6(1 \cdot 7)$ \\
$\mathrm{PaO}_{2}(\mathrm{kPa})$ & $2 \cdot 9-13 \cdot 5$ \\
$\mathrm{PaCO}_{2}(\mathrm{kPa})$ & \\
& $9 \cdot 3(2 \cdot 3)$ \\
& $4 \cdot 2-19 \cdot 1$ \\
& $7 \cdot 1(1 \cdot 6)$ \\
\hline
\end{tabular}

$\mathrm{FEV}_{1}=$ forced expiratory volume in one second; $\mathrm{FVC}=$ forced vital capacity; $\mathrm{PaO}_{2}, \mathrm{PaCO}_{2}=$ arterial oxygen and carbon dioxide tensions.

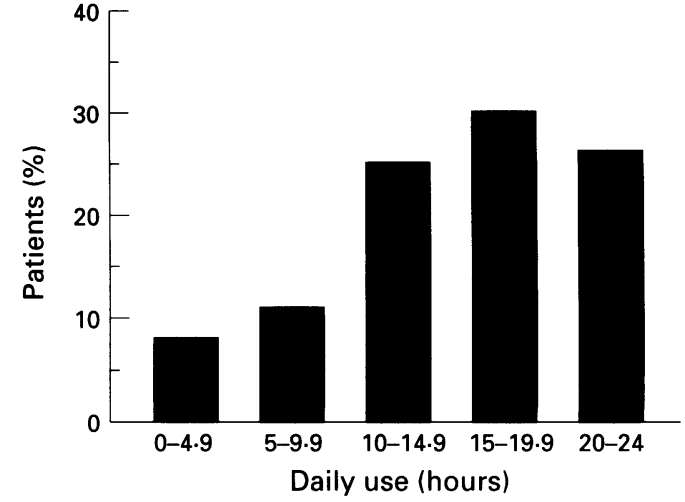

Breakdown of the daily hours of use of long term oxygen therapy by patients prescribed it.

measured. In $19 \%$ the $\mathrm{PaO}_{2}$ was $\geqslant 7 \cdot 3 \mathrm{kPa}$ and in $15 \%$ it was not measured.

At prescription $45 \%$ of patients were shown to be satisfactorily oxygenated with a $\mathrm{PaO}_{2}$ of $>8 \mathrm{kPa}$ while breathing oxygen. Ninety seven percent of patients were followed up. In 56\% arterial blood gas tensions were measured at least once when either breathing air or oxygen in the 12 months after prescription. However, $15 \%$ of these measurements were performed when the patients were clinically unstable, usually during an admission with an acute exacerbation of their condition.

In the three years from 1 October 1989 $60 \%$ of patients died, 19 within four weeks of prescription. The annual cost of an oxygen concentrator in Scotland is approximately $£ 1000$. Expenditure for the period October 1989 to September 1991 was $£ 413976$. Of the 632 oxygen concentrators, 304 were prescribed in the first year and 328 in the second. In comparison over the same period $£ 2634492$ was spent on oxygen cylinders.

\section{Discussion}

All concentrators in Scotland are now prescribed by respiratory physicians. The 632 concentrators prescribed (12 per 100000 population) is similar to the average annual rate of prescription in the UK of 8000 or 16 per 100000 population. ${ }^{4}$

As expected, most patients prescribed LTOT had a diagnosis of COPD (79\%). Mean compliance in our study was similar to that found in previous studies at 15 hours daily. ${ }^{45} \mathrm{Com}$ pliance ranged widely with only $56 \%$ of patients using their concentrator for 15 or more hours daily. Walshaw and coworkers found that less oxygen was prescribed on the advice of a general practitioner ( 10.6 hours daily) than either a non-respiratory physician $(14 \cdot 2$ hours) or a respiratory physician ( 13.5 hours), ${ }^{6}$ and that $62 \%$ of patients prescribed LTOT by a respiratory physician used their concentrator for at least 15 hours daily while only $38 \%$ of those prescribed by a general practitioner did so. ${ }^{5}$ Thus it does appear that compliance is better, although still rather poor, in patients prescribed LTOT by respiratory physicians.

The most obvious problem related to compliance with the guidelines was that $61 \%$ of 
patients were prescribed LTOT when clinically unstable, usually while an inpatient at the end of an exacerbation. It is also of concern that $22 \%$ and $15 \%$, respectively, of patients with COPD were prescribed LTOT without evidence of either $\mathrm{FEV}_{1}$ or $\mathrm{PaO}_{2}$ having been measured.

In our study $14 \%$ of patients were still smoking when prescribed LTOT, in breach of the guidelines. There is obvious concern over safety as well as uncertainty as to the likely benefit of LTOT in patients who continue to smoke. In two other studies $19 \%$ and $20 \%$ of patients continued to smoke at prescription. ${ }^{45}$

Thus, there is still considerable room for improvement in compliance and adherence to the guidelines even when LTOT is prescribed by respiratory physicians. Almost all patients in our study were followed up in a respiratory clinic where continuing patient education and encouragement can be given. Regular follow up at least twice yearly by a respiratory consultant is now recommended by the British Thoracic Society. ${ }^{7}$ The guidelines state that the aim of LTOT is to increase the $\mathrm{PaO}_{2}$ to $8 \mathrm{kPa}$ or more without excessive hypercapnia. However, at prescription only $59 \%$ of patients had arterial blood gas tensions measured breathing oxygen, with $45 \%$ demonstrating satisfactory oxygenation. It is also important to ensure that patients continue to fulfil the criteria, but only $56 \%$ had further arterial blood gas measurements during the following two years - again less than half when clinically stable. This is particularly relevant as most patients are assessed for LTOT when clinically unstable and thus the $\mathrm{PaO}_{2}$ may continue to improve for up to three months following an exacerbation. Any patients who are prescribed domiciliary oxygen at the end of an exacerbation should be reviewed six weeks and three months after prescription when blood gas tensions on air should be measured to ensure that they still require LTOT. Ideally, LTOT should not be prescribed until patients are reviewed as outpatients when stable. Home checks of pulse or ear oximetry are recommended annually to confirm that the prescription remains appropriate and effective. ${ }^{7}$

The number of deaths after prescription and the age of the patients suggests that LTOT is being prescribed late in the course of the disease. In our study $31 \%$ were over the age of 70. Reluctance to prescribe earlier may relate to the lack of alternative modes of delivery tailored to different patient needs. Liquid oxygen was available during the MRC trial and is still available in the US and in Continental Europe. It is preferred to gaseous oxygen, allowing more mobile patients clear benefit with portable oxygen. ${ }^{9}$ Although liquid oxygen is more expensive it may encourage treatment earlier in the course of the disease; compliance may also increase, leading to improved survival.

This study was supported by the Scottish Home and Health Department and the British Lung Foudation.

1 Medical Research Council Working Party. Long term domiciliary oxygen therapy in chronic hypoxic cor pulmonale complicating chronic bronchitis and emphysema. Lancet 1981;i:681-6.

2 Department of Health. Domiciliary oxygen therapy service. Drug Tariff. London: HMSO, November 1990: Part X.

3 Scottish Home and Health Department. Provision of oxygen concentrators to the domiciliary oxygen therapy service. 1989.

4 Restrick LJ, Paul EA, Braid GM, Cullinan P, Moore-Gillon J, Wedzicha JA. Assessment and follow up of patients prescribed long term oxygen treatment. Thorax 1993;48: prescribed

5 Walshaw MJ, Lim R, Evans CC, Hind CRK. Prescription of oxygen concentrators for long term oxygen treatment: reassessment in one district. BMF 1988;297:1010-2.

6 Walshaw MJ, Lim R, Evans CC, Hind CRK. Factors influencing the compliance of patients using oxygen concentrators for long-term home oxygen therapy. Respir Med 1990;84:331-3.

7 British Thoracic Society. Recommendations for oxygen concentrators for long term domiciliary oxygen treatment with adults. BTS News 1993; No. 11.

8 Levi Valensi P, Weitzenblum E, Pedinelli JL, Racineux JL, Duwoos H. Three month follow-up of arterial blood gas determinations in candidates for LTOT. Am Rev Respir Dis 1986;133:547-51.

9 Walters MI, Edwards PR, Waterhouse JC, Howard P. Long term domiciliary oxygen therapy in chronic obstructive pulmonary disease. Thorax 1993;48:1170-7. 